\title{
Rancang Bangun Media Pembelajaran Mini Trainer IC 555
}

\author{
Irma Yulia Basri ${ }^{1 *}$, Arsyfadhillah ${ }^{1}$, Dedy Irfan ${ }^{2}$, Thamrin ${ }^{2}$ \\ ${ }^{1}$ Jurusan Teknik Otomotif, Fakultas Teknik, Universitas Negeri Padang \\ ${ }^{2}$ Jurusan Teknik Elektronika, Fakultas Teknik, Universitas Negeri Padang \\ *Corresponding author, e-mail: irmayuliabasri@yahoo.com
}

\begin{abstract}
Abstrak - Universitas Negeri Padang (UNP) merupakan salah satu perguruan tinggi negeri yang mencetak lulusan untuk siap kerja. Perkembangan dunia industri khusus nya di bidang otomotif yang mengarah ke sistem elektronik, mau tidak mau Jurusan Teknik Otomotif FT UNP harus membekali lulusannya dengan kemampuan yang relevan dengan tuntutan dunia kerja tersebut. Pembelajaran Listrik dan Elektronika merupakan mata kuliah yang angka kegagalannya cukup tinggi bagi mahasiswa. Berbagai upaya sudah dilakukan oleh dosen pembina mata kuliah untuk meningkatkan hasil belajar mahasiswa, akan tetapi hasilnya masih belum memuaskan. Pembelajaran sudah dilakukan dengan menggunakan media power poin akan tetapi hasilnya belum maksimal dalam pencapaian hasil belajar mahasiswa di bidang Listrik dan Elektronika. Berdasarkan penelitian yang sudah dilakukan para ahli, salah satu cara untuk meningkatkan kualitas pembelajaran adalah dengan menggunakan media pembelajaran yang lebih inovatif, bersifat nyata dan langsung bisa diamati, salah satunya adalah mini trainer IC 555 .
\end{abstract}

\section{Kata kunci : Media Pembelajaran, Mini Trainer IC 555, Hasil Belajar}

\begin{abstract}
Padang State University (UNP) is one of the state universities that prints graduates to be ready for work. The development of the world of industry specifically in the automotive field that leads to electronic systems, inevitably the Automotive Engineering Department FT UNP must equip its graduates with capabilities that are relevant to the demands of the workforce. Learning electricity and electronics is a subject that has a high failure rate for students. Various efforts have been made by the lecturers to improve student learning outcomes, but the results are still not satisfactory. Learning has been done using power points, but the results have not been maximized in achieving student learning outcomes in the field of electricity and electronics. Based on research that has been conducted by experts, one way to improve the quality of learning is to use more innovative instructional media, are real and can directly be observed, one of which is a small trainer IC 555.
\end{abstract}

Keywords: Learning Media, Small Trainer IC 555, Learning Outcomes.

This is an open access article distributed under the Creative Commons 4.0 Attribution License, which permits unrestricted use, distribution, and reproduction in any medium, provided the original work is properly cited. C2018 by Author and Universitas Negeri Padang

\section{Pendahuluan}

Pengembangan kualitas manusia pada saat ini menjadi keharusan, terutama dalam memasuki era ilmu pengetahuan dan teknologi, agar generasi muda tidak menjadi korban dari perkembangan globalisasi itu sendiri. Peningkatan kualitas sumber daya manusia dapat dilakukan dengan penambahan ilmu pengetahuan masing-masing individu, terutama dikalangan mahasiswa. Namun masing-masing individu memiliki cara pemahaman yang berbeda-beda dalam proses belajar mengajar. Proses belajar mengajar ada beberapa faktor yang mempengaruhinya yaitu faktor internal (diri mahasiswa itu sendiri) dan faktor eksternal (dari luar diri mahasiswa itu sendiri). Faktor eksternal meliputi pengajar, fasilitas dan lingkungan belajar mahasiswa. Dosen dituntut berinovasi dalam mengembangkan materi untuk menciptakan keberhasilan mahasiswa pada mata kuliah yang dibimbingnya. Salah satu inovasi yang dapat dilakukan adalah dengan memaksimalkan penggunaan media pembelajaran atau alat peraga. Media pembelajaran bertujuan agar komunikasi antara mahasiswa dengan dosen berlangsung dengan baik dan materi pembelajaran dapat tersampaikan lebih efektif dan efisien. 
Penelitian yang berkaitan dengan dampak positif penggunaan media pembelajaran bagi peserta didik sudah banyak dilakukan. Dari hasil penelitian $70 \%$ responden mengungkapkan lebih mudah memahami materi kimia dengan bantuan media pembelajaran CD Interaktif [1]. Dan penggunaan media pembelajaran trainer Intalasi Listrik mampu meningkatkan hasil belajar siswa, pada siklus pertama siwa yang berhasil dalam pembelajaran adalah $83,33 \%$, sedangkan pada siklus kedua meningkat menjadi $100 \%$ [2]. Penelitian lainnya berkaitan dengan media pembelajaran mengungkapkan bahwa penerapan media pembelajaran Trainer PLC Omron dan software X-Programmer pada mata pelajaran PLC kelas XII TIPTL SMK Negeri 1 Bukittinggi mampu meningkat hasil belajar siswa dengan gain score 0,407 dan 0,7625 [3].

Media pembelajaran berupa trainer komponen elektronika sangat berguna untuk mengetahui fungsi, prinsip kerja dan aplikasi dari dari masingmasing komponen elektronika. Media pembelajaran ini sangat membantu mahasiswa dalam mendalami karakteristik komponen elektronika, sehingga relevan antara pembelajaran teori dengan pratikum. Di Universitas Negeri Padang khususnya Jurusan Teknik Otomotif belum ada media pembelajaran yang memadai mata kuliah Listrik dan Elektronika, sehingga tidak seluruh materi bisa diserap oleh mahasiswa, hal ini dapat dilihat dari tingginya tingkat pengulangan mata kuliah Listrik dan Elektronika oleh mahasiswa Jurusan Teknik Otomotif FT UNP. [4] mengungkapkan terdapat pengaruh positif penggunaan bahan ajar berbasis Arduino terhadap prestasi belajar mahasiswa untuk pembelajaran kuliah Mikrokontroler di Politama Surakarta. Hasil penelitian menunjukkan rata-rata nilai post-test kelas eksperimen $(26,49)$ lebih tinggi daripada rata-rata nilai post-test kelas kontrol $(22,03)$. Penelitian yang dilakukan oleh [5] mengungkapkan penggunaan media trainer kelistrikan terhadap 40 orang responden mampu meningkatkan rata-rata kelas hasil belajar siswa dari 73 poin menjadi 82,36 poin.

Dampak penggunan media pembelajaran terhadap peningkatan hasil belajar siswa sangat sgnifikan berdasarkan penelitian yag sudah dilakukan, untuk itu peneliti tertarik untuk membuat media pembelajaran yang inovatif. Media pembelajaran ini didesain untuk memudahkan peserta didik mempelajari komponen elektronika. Salah satu media pembelajaran yang peneliti rancang tersebut adalah mini trainer IC 555. Keunggulan media pembelajaran ini dibandingkan dari media yang beredar dipasaran adalah bentuk yang lebih kecil sehingga efektif untuk dibawa kemana-mana. Mini trainer yang dirancang memperlihatkan prinsip kerja dan aplikasi dari IC 555.

\section{StUdi PUSTAKa}

Produktivitas IC adalah jenis komponen semikonduktor yang penggunaannya sangat luas. Salah satu keuntungan penggunaan komponen ini adalah tidak memerlukan tempat yang luas sehingga rangkaian elektronika yang memanfaatkan komponen ini bentuknya bisa lebih peraktis. IC merupakan suatu rangkaian terpadu yang dibuat pada sekeping kecil silikon dalam bentuk kemasan tunggal. yang terdiri atas beberapa komponen elektronika yang disatukan. Komponen-komponen tersebut adalah Transistor, Resistor, Kapasitor, Dioda, dan beberapa komponen lainnya. Komponen IC banyak dipakai dalam mesin komputer. Namun dalam teknik komputer istilah IC sering disebut dengan CHIP. Namun Resistor dan Kapasitor biasanya tidak dipergunakan lagi karena membutuhkan ruangan yang lebih besar sehingga harganya lebih mahal. Jumlah komponen yang membentuk IC mencapai ribuan dan mempunyai aplikasi yang berbeda, seperti IC ampifier daya rendah jenis TL741 sampai daya tinggi jenis STK 32, IC frekuensi Radio, dan lain-lain.

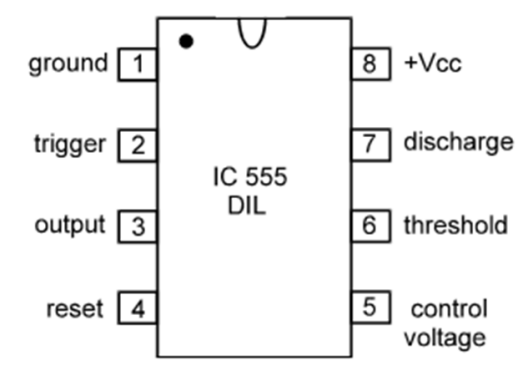

Gambar 1. Pin IC NE 555 [6]

Bentuk IC juga bermacam-macam, mulai dari yang berkaki tiga sampai yang berkaki 200 buah. Untuk menentukan kaki-kaki IC tersebut, memang tidak ada acuannya, sebab kaki-kaki tersebut disesuaikan dengan kebutuhan aplikasi yang dibuat oleh pabrik, tetapi ada beberapa IC yang kaki-kakinya ditentukan dengan acuan tertentu, yaitu kaki nomor satu di tandai dengan berupa titik atau tanda lainnya. 


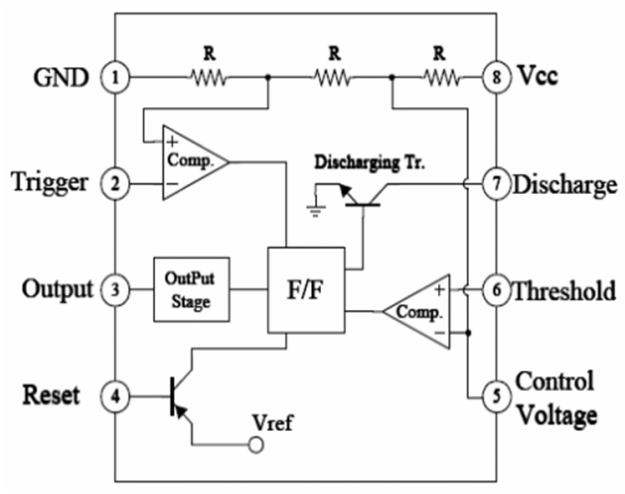

Gambar 2. Skema internal IC NE 555 [6]

Keterang dari masing-masing pin pada IC 555:

- $\quad$ Pin 1 Ground (0V)

Pin 1 Ground (OV) merupakan, pin input dari sumber tegangan DC paling negatif.

- $\quad$ Pin 2 Trigger

Pin 2 trigger merupakan, input negatif dari lower komparator (komparator B) yang menjaga osilasi tegangan terendah kapasitor pada 1/3 Vcc dan mengatur RS flip-flop.

- $\quad$ Pin 3 Output

Pin 3 Output merupakan pin keluaran dari IC 555.

- $\quad$ Pin 4 Reset

Pin 4 Reset merupakan pin yang berfungsi untuk me-reset latch didalam IC yang akan berpengaruh untuk menjadikan kondisi awal dari IC. Pin ini tersambung ke suatu gate (gerbang) transistor bertipe PNP, jadi transistor akan aktif jika diberi logika low. Biasanya pin ini langsung dihubungkan ke $\mathrm{V}_{\mathrm{CC}}$ agar tidak terjadi reset.

- Pin 5 Control Voltage

Pin 5 Control voltage berfungsi untuk mengatur kestabilan tegangan referensi input negative (komparator A), pin ini bisa dibiarkan tergantung (diabaikan), tetapi untuk menjamin kestabilan referensi komparator A, biasanya dihubungkan dengan kapasitor berorde sekitar $10 \mathrm{nF}$ ke pin ground.

- $\quad$ Pin 6 Threshold

Pin 6 threshold terhubung ke input positif (komparator A) yang akan me-reset RS flipflop ketika tegangan pada pin 6 mulai melebihi 2/3 Vcc.

- $\quad$ Pin 7 Discharge
Pin 7 discharge terhubung ke open collector transistor internal (Tr) yang emitternya terhubung ke ground.

\section{- $\quad$ Pin $8 V_{C C}$}

Pin $8 \mathrm{~V}_{\mathrm{CC}}$ untuk menerima supply $\mathrm{DC}$ voltage. Biasanya akan bekerja optimal jika diberi $5 \mathrm{~V} \mathrm{~s} / \mathrm{d}$ 15V. Supply arusnya dapat dilihat di datasheet, yaitu sekitar $10 \mathrm{~mA} \mathrm{~s} / \mathrm{d}$ $15 \mathrm{~mA}$.

IC 555 pewaktu ini menggabungkan sebuah osilator relaksasi, dua pembanding, flip-flop RS, dan sebuah Transistor pembuang. IC serbaguna ini mempunyai banyak manfaat sehingga telah menjadi standart industri. Dan berfungsi sebagai rangkaian pewaktu monostable dan isolator stabil.

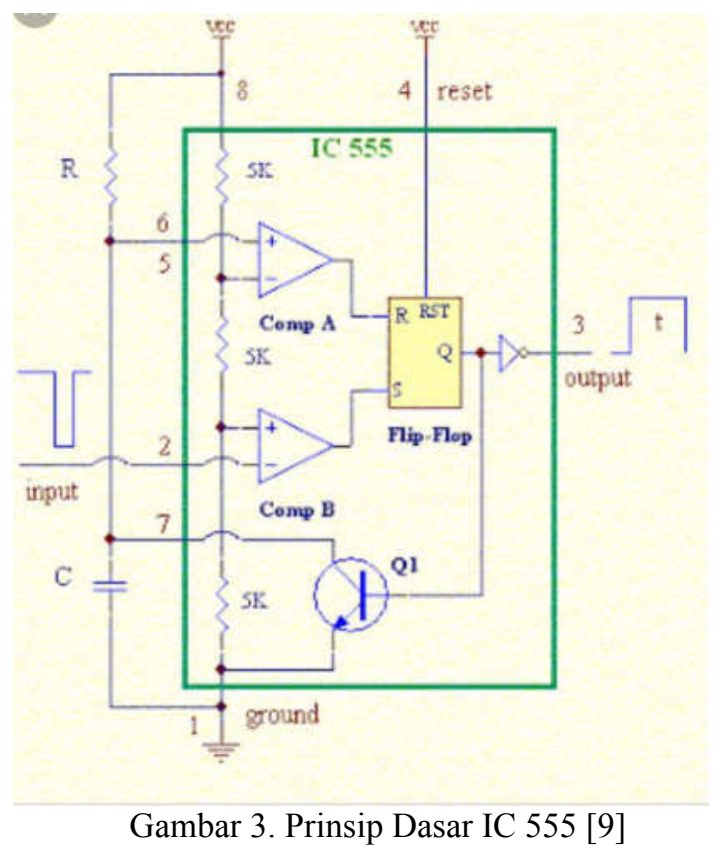

Keunggulan dari IC 555 adalah:

- Tingkat presisi yang lebih tinggi dalam menghasilkan panjang pulsa.

- Panjang pulsa tidak dipengaruhi oleh perubahan-perubahan pada tegangan catu.

- Dapat dibangkitkannya pula yang sangat panjang (hingga mencapai 1 jam, misalnya).

- Hanya dibutuhkannya beberapa komponen tambahan.

- Arus output dapat mencapai hingga $200 \mathrm{~mA}$, yang cukup besar untuk menyalakan sebuah lampu atau mengaktifkan sebuah relay.

Gambar 3 merupakan rangkaian internal IC 555 , inputnya terdiri dari dua buah komparator, komparator A, inputnya merupakan threshold (pin 6) dari IC 555 atau input non inverting. 
Komparator $\mathrm{B}$, input non inverting komparator $\mathrm{B}$ diambil dari pin 2 (trigger) IC 555. Lalu akan menjadi masukan unuk RS Flip Flop, output dari RS flip-flop terhubung dengan output IC 55 (pin $3)$.

Prinsip dasar dari IC 555 adalah sebagai rangkaian pengingat yang dikendalikan oleh RS Flip Flop. Output RS Flip Flop akan berlogika 1 jika masukan terminal $\mathrm{S}$ di set 1, meski kemudian terminal $\mathrm{S}$ sudah berlogika 0 , selagi terminal $\mathrm{R}$ dari RS Flip Flop belum berlogika 1 maka output RS Flip Flop akan tetap dalam kondisi High [6].

IC 555, jika pin 2 (trigger) telah mendapatkan sinyal dan dalam kondisi ON, selagi pin 6 (threshold) tidak berlogika 1 (high), meskipun pin 2 (trigger) tidak di berikan tegangan kembali IC 555 akan tetap dalam keadaan high atau ON berlogika 1. Seperti yang terdapat pada tabel 1 . Prinsip kerja IC 555 secara detail dapat dilihat pada tabel 1.

Tabel 1. Prinsip Keja IC 555.

\begin{tabular}{|c|c|c|c|c|c|c|}
\hline \multirow{2}{*}{$\begin{array}{c}\text { Pin } 6 \\
\text { (thresho } \\
\text { ld) }\end{array}$} & \multirow{2}{*}{$\begin{array}{c}\text { Pin } 2 \\
\text { (trigg } \\
\text { er) }\end{array}$} & \multicolumn{3}{|c|}{$\begin{array}{l}\text { RS flip- } \\
\text { flop }\end{array}$} & \multirow[t]{2}{*}{$\begin{array}{l}\text { Pin } 3 \\
\text { (outp } \\
\text { ut) }\end{array}$} & \multirow[t]{2}{*}{$\begin{array}{c}\text { Keteran } \\
\text { gan }\end{array}$} \\
\hline & & $\mathrm{R}$ & $\mathrm{S}$ & $\mathrm{Q}$ & & \\
\hline 0 & 0 & 0 & 0 & 0 & 0 & OFF \\
\hline 0 & 1 & 0 & 1 & 1 & 1 & $\mathrm{ON}$ \\
\hline 0 & 0 & 0 & 1 & 1 & 1 & ON \\
\hline 1 & 0 & 1 & 0 & 0 & 0 & OFF \\
\hline 0 & 0 & 0 & 0 & 0 & 0 & $0 \mathrm{FF}$ \\
\hline 0 & 1 & 0 & 1 & 1 & 1 & ON \\
\hline 0 & 0 & 0 & 1 & 1 & 1 & ON \\
\hline
\end{tabular}

IC 555 berdasarkan penerapannya terdiri dari tiga operasi yaitu operasi monostabil, operasi astabil dan operas bistabil.

\section{A. Operasi Monostabil ( Stabil Tunggal)}

Rangkaian ini hanya memerlukan sedikit rangkaian tambahan untuk dapat mengoperasikannya, yaitu sebuah resistor $\left(\mathrm{R}_{\mathrm{A}}\right)$ dan sebuah kapasitor (C1) serta kapasitor (C2) untuk menstabilkan tegangan referensi pada upper comparator (komparator-A). IC ini memanfaatkan rangkaian tambahan tersebut untuk men-charge dan men-discharge kapasitor $\mathrm{C} 1$ melalui resistor $\mathrm{R}_{\mathrm{A}}$. fungsi rangkaian ini adalah untuk menghasilkan pulsa tunggal pada pin-3 dengan waktu tertentu jika pin-2 diberi trigger/dipicu. Pada keadaan awal, keluaran IC-nya berlogika ' 0 '.
Dapat dilihat pada gambar bahwa terdapat rangkaian pembagi tegangan untuk input referensi komparator-A dan komparator-B. Prinsip kerja komparator yaitu jika $V_{d}$ (beda potensial input inverting dan input non-invertingnya) bernilai positif, maka komparator akan mengeluarkan output berlogika ' 1 '. Jika diberi trigger dari logika ' 1 ' ke logika ' 0 ' pada pin-2, maka $\mathrm{V}_{\mathrm{d}}$ pada komparator-B akan bernilai positif dan berhasil mengeluarkan output high. Output ini akan menset RS flip-flop (memberi keluaran IC logika '1') untuk beberapa saat, seiring dengan itu, transistor Q1 akan off (open) dan kapasitor C1 akan melakukan pengesian sebelum akhirnya RS flipflop akan direset oleh komparator-A dan kapasitor C1 melakukan discharge melalui resistor R1 secara transient. Lamanya pulsa tunggal yang dihasilkan sekitar $\mathrm{t}=1.1 \mathrm{R}_{\mathrm{A}} \mathrm{C}_{1}[9]$.

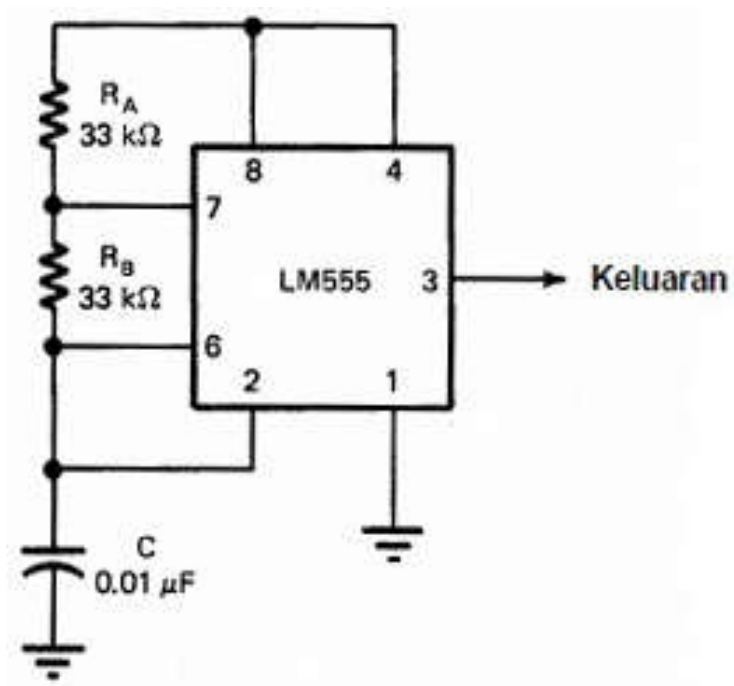

Gambar 4. Rangkaian IC 555 Monostabil [9]

Pada bagan rangkaian pewaktu monostabil 555, pin 5 (kendali) dipintaskan ketanah melalui kapasitor kecil, yang biasanya bernilai sekitar $0,01 \mu \mathrm{F}$. Susunan ini menyajikan penapisan derau bagi tegangan kendali. Pin 4 yang di tanahkan akan merintangi kerja pewaktu 555. Untuk mencegah reset yang tak disengaja, pin 4 biasanya dihubungkan dengan tegangan catu, seperti tampak pada Gambar 3. Pewaktu monostabil 555 menghasilkan pulsa tunggal dengan lebar yang di tentukan oleh $\mathrm{R}$ dan $\mathrm{C}$, pulsa dimulai dengan tepi naik dari masukan pemicu negatif.

\section{B. Operasi Astabil IC 555}

Rangkaian Astable agak berbeda dari rangkaian monostable. Rangkaian astable akan menghasilkan sinyal kotak yang terus berdetak 
dengan duty cycle tertentu selama catu tegangan tidak dilepaskan. Prinsip kerjanya, jika pada rangkaian monostable dipicu dengan tegangan berlogika high ke low (kurang dari $1 / 3 \mathrm{Vcc}$ ) pada pin-2, rangkaian astable ini dibuat untuk memicu dirinya sendiri. Rangkaian ini memanfaatkan osilasi tegangan pada kapasitor disekitar $1 / 3 \mathrm{Vcc}$ sampai $2 / 3$ Vcc. Komponen eksternal yang diperlukan adalah sebuah kapasitor (C1) dan dua buah resistor $\left(\mathrm{R}_{\mathrm{A}}\right.$ dan $\left.\mathrm{R}_{\mathrm{B}}\right)$. Adapun untuk kestabilan tegangan referensi komparator-A, digunakan sebuah kapasitor lagi (C2) pada pin-5 sebesar $10 \mathrm{nF}$ ke ground. Sedikit terkait dengan deskripsi pin yang telah dibahasi diatas, saat transistor Q1 ON maka resistansi menuju ground pada emitternya sangat kecil, sehingga ground seakan-akan tersambung diantara kedua resistor. Namun ketika transistor Q1 off, resistansi antara collector dan emitternya sangat besar dan sulit dilewati arus, seakan terjadi open circuit. Pada akhirnya output yang terjadi berupa sinyal kotak akan mendetak secara kontinu dengan frekuensi tertentu seiring dengan berosilasinya tegangan pada kapasitor di 1/3 Vcc sampai 2/3 Vcc. Osilasi yang dimaksud disini dapat dijelaskan yaitu, sesaat tegangan kapasitor melebihi $2 / 3$ Vcc komparator-A mengeluarkan output high yang akan me-reset RS flip-flop dan tegangan pada kapasitor akan turun(discharging) secara transient. Sesaat tegangan pada kapasitor $\mathrm{C} 1$ berkurang dari $1 / 3$ Vcc, output komparator B akan berlogika high dan men-set RS flip-flop, selanjutnya tegangan kapasitor akan naik secara transient (charging) dan begitu seterusnya berosilasi menghasilkan pulsa. Jadi, saat berosilasi tegangan kapasitor tidak akan kurang dari 1/3 Vcc dan melebihi $2 / 3$ Vec [7] [9].

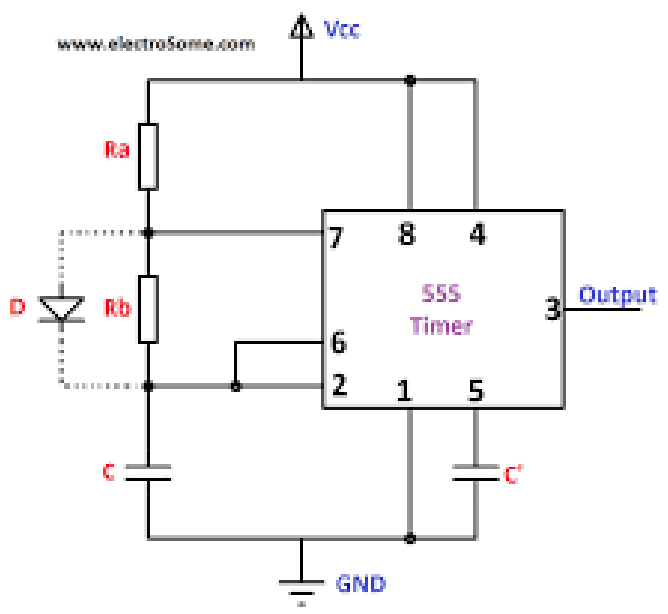

Gambar 5. Rangkaian IC 555 Astabil [5]
Pada bagan skematik tampak bahwa penyemat 4 (reset) dihubungkan dengan tegangan catu dan penyemat 5 (kendali) dipintas ketanah melalui kapasitor $0,01 \mu \mathrm{F}$ IC 555 astabil ini sering disebut sebagai multivibrator astabil karena menghasilkan pulsa-pulsa persegi yang keluar terus menerus.

\section{Operasi Bi-Stable}

Bi-Stable multivibrator adalah jenis lain dari multivibrator yang mirip dengan monostable multivibrator.

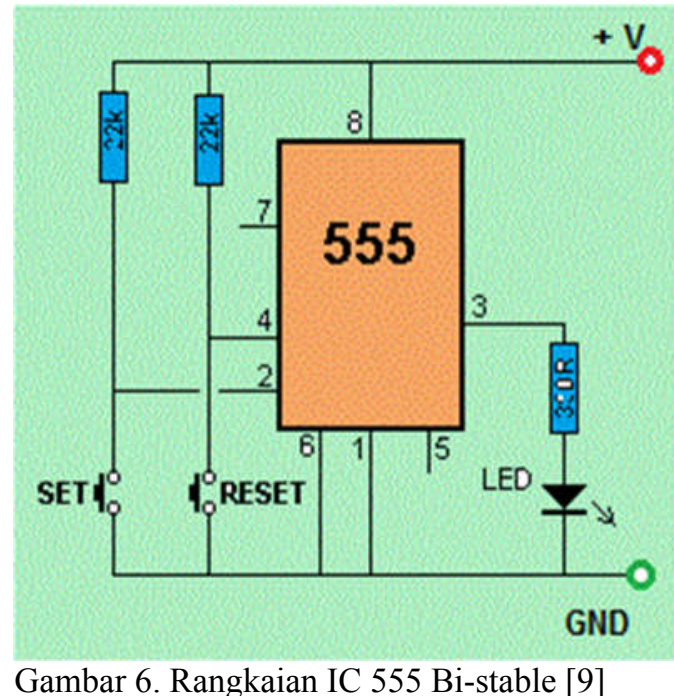

Multivibrators bi-stable memiliki dua kondisi yang stabil (maka nama: "Bi" berarti dua) dan mempertahankan keadaan output yang diberikan tanpa batas waktu kecuali pemicu eksternal diterapkan memaksanya untuk mengubah keadaan. Multivibrator bi-stable dapat beralih dari satu kondisi stabil ke kondisi yang lain dengan penerapan pulsa memicu eksternal. Multivibrator bi-stabil membutuhkan dua pulsa memicu eksternal sebelum kembali ke keadaan semula. Multivibrator bi-stable memiliki dua keadaan yang stabil yang lebih dikenal sebagai flip-flop [8].

Diskrit bi-stable multivibrator adalah dua keadaan perangkat non-regeneratif dibangun dari dua lintas digabungkan transistor beroperasi sebagai "ON-OFF" switches transistor. Dalam masing-masing dua kondisi, salah satu transistor dipotong-off sementara transistor lain dalam kejenuhan, ini berarti bahwa sirkuit bi-stable mampu tersisa tanpa batas dalam keadaan stabil. Untuk mengubah keadaan bi-stable, rangkaian bistable membutuhkan pulsa pemicu (clock) dan rangkaian flip flop.

Bi-stable multivibrator akan stabil di kedua kondisi dengan menggunakan dua transistor. Jika 
transistor pertama OFF maka transistor kedua akan ON atau jika transistor pertama ON maka transistor kedua akan OFF. Kita misalkan bahwa saklar berada di posisi kiri, posisi "A". Basis transistor1 di wilayah cut-off-nya akanmenghasilkan output pada Q. Itu berarti bahwa transistor 2 adalah $\mathrm{ON}$, dimana basisnya terhubung ke Vcc melalui kombinasi seri resistor R1 dan R2. Jika transistor 2 adalah ON maka transistor 1 akan OFF, sehingga Q' berlogik 0 (kebalikan dari keluaran Q).

Jika saklar kini bergerak ke kanan, posisi B, transistor 2 akan beralih OFF dan transistor 1 akan beralih ON melalui kombinasi resistor R3 dan R4 menghasilkan output di $\mathrm{Q}=$ nol dan output pada Q' adalah 1 [7] [9]. Multivibrator monostable output tergantung pada RC dan komponen umpan balik yang digunakan, sedangkan output multivibrator bistable tergantung pada penerapan dua pulsa memicu individu, beralih posisi A atau posisi $\mathrm{B}$.

\section{Aplikasi IC 555}

IC 555 sebagai Timer

Sebuah versi daya-rendah dari IC 555 adalah IC tipe 7555.IC ini dapat membangkitkan pulsa-pulsa yang bahkan lebih panjang lagi, dengan arus output hingga $100 \mathrm{~mA}$. Dibawah ini adalah gambar rangkaian monostabil yang memanfaatkan IC 7555.

IC 555 beroperasi dengan tegangan catu $4,5 \mathrm{~V}$ hingga $16 \mathrm{~V}$. IC ini membutuhkan kapasitor $\mathrm{C} 1$ yang disambungkan diantara pin 5 dan jalur catu 0V. Panjang pulsa yang dihasilkan ditentukan oleh resistor pewaktu (R) dan kapasitor pewaktu (C). Panjang pulsa itu sendiri $(t)$ adalah:

$t=$ waktu(detik)

$$
t=1,1 R C
$$

$\mathrm{R}=$ Tahanan $(\mathrm{ohm})$

$C=$ Kapasitansi(farad)

Dengan nilai-nilai yang diperlihatkan dalam gambar 7, pulsa yang dihasilkan rangkaian dapat bertahan hingga 10 detik.

Didapat dari persamaan :

$$
\begin{aligned}
& t=1,1 R C \\
& t=1,1 \times 10 \mathrm{k} \Omega \times 10 \mu \mathrm{F} \\
& t=10 \mathrm{~s}
\end{aligned}
$$

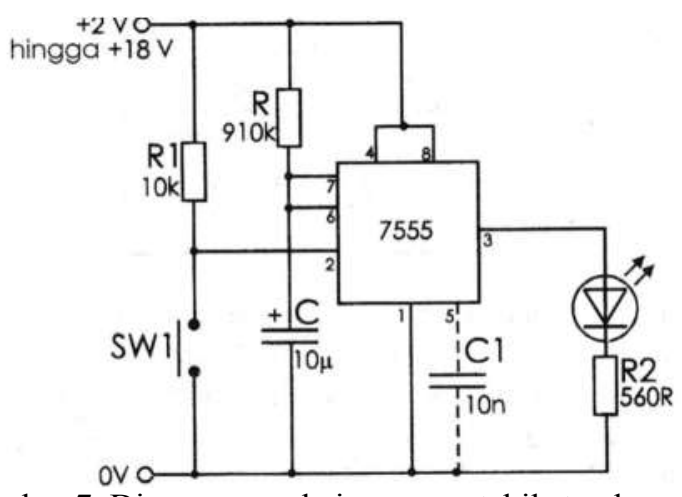

Gambar 7. Diagram rangkaian monostabil standar yang memanfaatkan IC 7555 [9]

Trigger pada pin 2, dalam keadaan normal, berada pada level tegangan catu positif. Pada gambar 7, diperlihatkan sebuah resistor pull-up R1 yang berfungsi sebagai triger. Rangkaian timer (pewaktu) dipicu menjadi aktif oleh sebuah pulsa 'rendah' yang sangat singkat. Saat saklar di-ONkan maka LED akan menyala selama 10 detik kemudian OFF kembali. Saat posisi OFF trigger (pin 2) terhubung ke groun (pin 1) $0 \mathrm{~V}$, dan output (pin 3) berada pada level low (0V). Output ini akan naik dalam waktu 10 detik dan output kembali 0 hingga mencapai tegangan catu positif, ketika timer dipicu menjadi aktif. Sebagian output pin 3 akan tinggal pada titik nol di akhir pulsa. Pin 4 adalah pin reset. Pin ini di sambungkan secara permanen ke jalur catu positif. Apabila pin ini secara sekejap disambungkan ke jalur catu $0 \mathrm{~V}$ ketika timer sedang membangkitkan sebuah pulsa, output timer (pulsa tersebut) saat itu juga akan berubah menjadi $0 \mathrm{~V}$ [9].

\section{METODE}

Penelitian ini merupakan jenis penelitian Research and and Development (Penelitian dan Pengembangan/ R\&D) dan penelitian eksperimen. [10] mengungkapan Metode penelitian R\&D digunakan untuk menghasilkan produk tertentu, dan menguji keefektifan produk tersebut. Strategi R \& D adalah Desain Produk, Validasi Desain, Revisi Desain, Ujicoba Produk.

\section{A. Desain Produk}

Mini Trainer transistor di rancang dengan menggunakan Software Circuit Maker dan gambar rancangan diedit menggunakan Microsoft Office. Ada 2 rancangan mini trainer IC 555

\section{B. Validasi Desain}

Validasi desain dilakukan oleh tenaga ahli supplier trainer/media pembelajaran yang selama ini sudah banyak memasarkan produk rakitan trainernya ke Pulau Sumatera, Jawa dan 
Kalimantan. Dengan validasi yang dilakukan kualitas rancangan menjadi lebih baik.

\section{Revisi Desain}

Desain yang direvisi menyangkut tata letak komponen didalam kemasan (acrylic). Tata letak komponen disesuaikan dengan besaran komponen yang ada, kemudian beberapa komponen yang ada di skema rangkaian diubah nilainya disesuaikan dengan nilai yang ada dipasaran.

\section{Ujicoba Produk}

Desain yang telah disempurnakan dilakukan perakitan dan ujicoba rangkaian yang dirakit. Setelah rangkaian berhasil dan data yang dihasilkan sesuai dengan teoritis, maka trainer baru dikemas menggunakan acrylic

\section{HASIL DAN PEMbahasan}

\section{A. Prosedur Perakitan.}

Perakitan media pembelajaran IC 555 terdiri dari berapa tahapan yaitu perancangan gambar kerja, perakitan komponen rangkaian, uji coba rangkaian, instalasi housing/box.

\section{Gambar kerja}

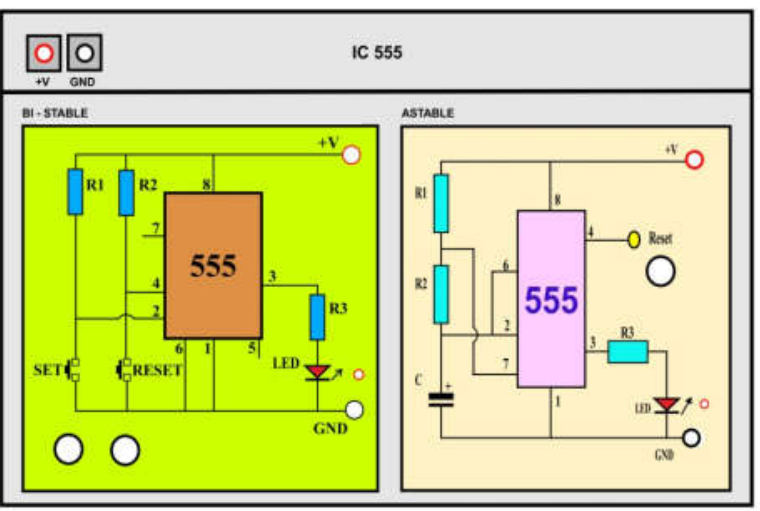

Gambar 8. Gambar Desain Mini Trainer IC 555

Dalam merancang skema rangkaian hal pertama yang dilakukan adalah merancang menggunakan kertas buram untuk menentukan rangkaian yang akan dibuat selanjutnya menggunakan aplikasi circuit maker, setelah rangkaian dibuat menggunakan cirkuit maker selanjutnya rangkaian masuk pada tahap pewarnaan, pada tahap ini rangkaian diedit pada aplikasi pain, setelah diedit gambar akan disusun pada microsoft word untuk menyusun tata letak komponen, jarak antara jamper dan komponen maupun mendesain tampilan gambar rangkaian yang akan dicetak seperti yang terlihat pada gambar 8 .

\section{Merakit komponen pada papan PCB}

Sebelum merakit komponen pada papan PCB ada beberapa langkah yang akan dilakukan yang terdiri dari beberapa tahap, diantaranya persiapan alat dan bahan serta komponen-komponen yang diperlukan untuk media pembelajaran mini trainer IC 555. Perakitan komponen pada papan PCB ada beberapa tahapan yang harus dilakukan mulai dari pengecekan komponen, penyusunan tata letak komponen, dan penyolderan komponen pada papan PCB.

Pada tahap pengecekan komponen pertama dilakukan peeriksaan seluruh komponen dalam kondisi baik dengan menggunakan multimeter pada posisi ohm meter, pada tahap pemeriksaan dipastikan seluruh komponen dalam keadaan baik. Setelah komponen diperiksa selanjutnya komponen disusun pada papan PCB sedemikian rupa, agar terlihat rapi dan penggunaan papan PCB menjadi efisien dan mudah dalam penyolderan komponen serta mudah dalam perakitannya pada housing. Seperti yang kerlihat pada gambar 9 .

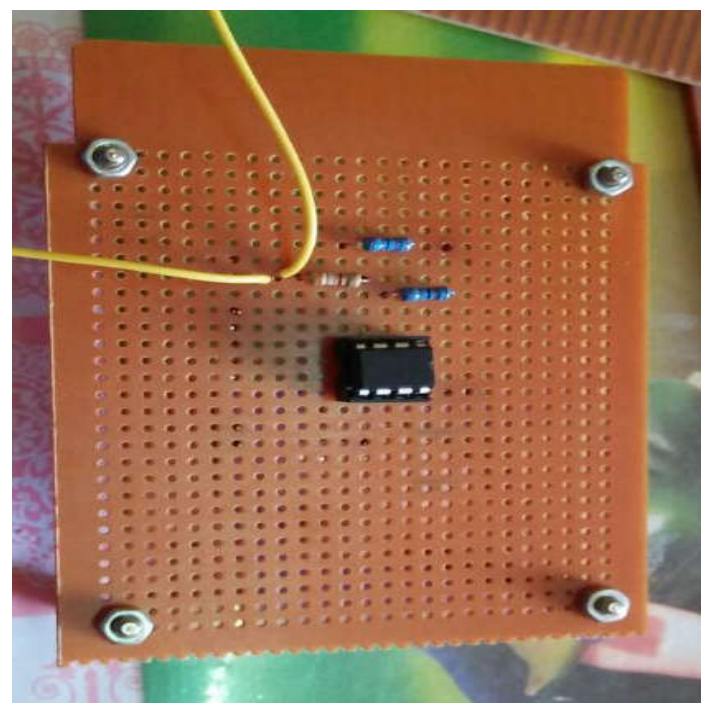

Gambar 9. Memasang komponen pada papan PCB sebelum di solder.

Setelah menyusun komponen pada papan PCB langkah selanjutnya adalah menyolder komponen pada PCB dan menghubungkanya sesuai dengan rangkaian. Sebelum menyolder komponen, panaskan alat solder terlebih dahulu agar solder yang dihasilkan baik dan kuat. Proses penyolderan usahakan alat solder dipegang dengan kemiringan $45^{\circ}$ yang terlihat pada gambar 10 . 


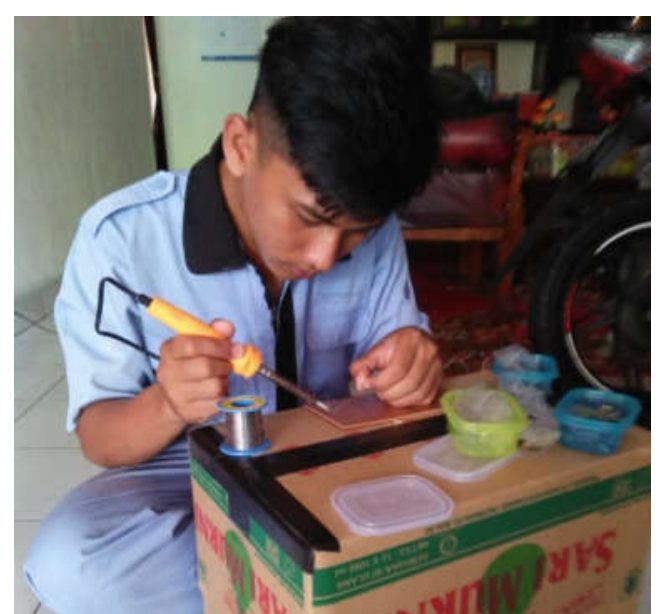

Gambar 10. Menyolder terminal-terminal komponen

3. Uji coba rangkaian

Uji coba rangkaian pada papan $\mathrm{PCB}(\mathrm{Gambar}$ 11) bertujuan untuk memastikan rangkaian bekerja sesuai kajian teoritis sebelum dipasang ke papan acrilic maupun box/housing. Sebelum melakukan uji coba pada papan PCB sebaiknya hubungkan black housing 1 pin male pada kabel jamper sesuai dengan gambar rangkaian kemudian hubungkan dengan baterai. Pada rangkaian ini terdapat dua rangkaian yaitu astable dan bi-stable.

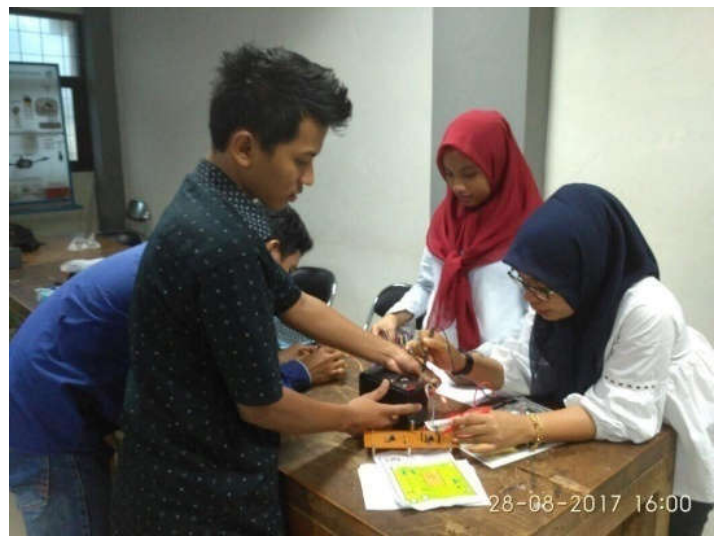

Gambar 11. Uji coba rangkaian IC 555 pada papan PCB

\section{a. Rangkaian Bi-Stable}

Pada rangkaian bi-stable terdapat dua push botton yang berfungsi sebagai SET dan RESET. Pada saat rangkaian dihubungkan pada Baterai maka rangkaian akan bekerja dengan tanda LED menyala pada saat tombol set di-on-kan dan akan mati pada saat tombol reset di-off-kan. Pada saat tombol Set diposisi ON, kaki dari pin 2 (trigger) akan berubah mencapai $1 / 3$ dari $\mathrm{V}_{\mathrm{CC}}$, maka Transistor internal akan trun-off. Saat Swich transistor yang off inilah akan menaikkan tegangan pin 6 IC 555 sehingga menyebabkan pin 3 (output) IC5 55 yang semula berlogika low (0) akan menjadi berlogika high (1) dan menyebabkan LED menyala.

Pada saat tombol Reset diposisi ON, maka pin 3(output) dari IC 555 akan berubah sesuai dengan tegangan threshold (pin 6). Ketika tegangan pin 6 melebihi $2 / 3$ dari $\mathrm{V}_{\mathrm{CC}}$ dan logika output pada pin 3 berlogika high, maka transistor internal akan-on, sehingga menurunkan tegangan threshold (pin 6) menjadi kurang dari $1 / 3$ dari $\mathrm{V}_{\mathrm{CC}}$. Selama interval ini output pada pin 3 akan berlogika low atau LED tidak akan menyala.

Setelah uji coba rangkaian, langkah selanjutnya yaitu proses uji coba pengukuran pin IC 555, sebagai contoh yaitu pin 3. Data lengkap dapat dilihat pada Tabel 2.

Pada terminal 3 merupakan tegangan keluaran dari IC. Tegangan keluaran IC tidak akan sama pada saat SET dan RESET. Pada saat set tegangan pin 6 terhubung dengan sumber Vcc, sehingga pin 6 dalam keadaan high, jika pin 6 high maka pin 3 akan berlogik 1, sehingga LED yang terhubung dengan pin 3 akan menyala.

Tabel 2. Data uji coba rangkaian BI- STABLE

\begin{tabular}{|c|c|c|c|}
\hline $\mathrm{V}_{\mathrm{S}}$ & Kondisi & $\begin{array}{c}\text { Pin } \\
\text { (Terminal) }\end{array}$ & $\begin{array}{c}\text { Tegangan } \\
(\mathrm{V})\end{array}$ \\
\hline \multirow{2}{*}{$\begin{array}{c}12,17 \\
\mathrm{~V}\end{array}$} & \multirow{2}{*}{$\mathrm{SET}$} & 3 (Output) & $10,67 \mathrm{~V}$ \\
\cline { 3 - 4 } & \multirow{2}{*}{ RESET } & 6(Threshold) & $1,3 \mathrm{mV}$ \\
\cline { 3 - 4 } & & 6(Thershold) & $0,9 \mathrm{~V}$ \\
\hline
\end{tabular}

Pada saat reset tegangan pada (pin 4) akan menjadi terlepas dari $\mathrm{V}_{\mathrm{CC}}$ maka transistor internal aktif yang akan mereset RS flip-flop yang menyebabkan tidak adanya sinyal pada pin 3(output) dari IC yang semulanya high akan menjadi low yang menyebabkan LED tidak menyala. Pada data hasil uji coba dapat dilihat bahwasanya tegangan yang dihasilkan sudah sesuai dengan teori.

\section{b. Rangkaian Astable}

Pada rangkaian astable hanya terdapat 1 push botton yang berfungsi sebagai RESET. Apabila tegangan baterai dihubungkan ke rangkaian maka LED akan menyala. Dan saat saklar reset di onkan maka LED akan off. Rangkaian IC 555 astable ini adalah rangkaian yang hanya menggunakan Resistor dan Kapasitor saja.

Pada rangkaian dapat dilihat bahwasanya Resistor 1 dihubungkan antara $+\mathrm{Vs}$ dengan terminal discharger (pin7). Resistor 2 dihubungkan antara pin 7 dan terminal treshold (pin 6) terhubung inputnya dengan pin 2 (triger) menjadi satu, dan Kapasitor dihubungkan antara 
terminal treshold dan ground.

Setelah uji coba rangkaian LED menyala langkah selanjutnya yaitu proses uji coba pengukuran kaki-kaki IC sebagai contoh yaitu kaki 3 dapat dilihat pada tabel 3. Pada saat sumber tegangan pertama kali diberikan, kapasitor akan terisi melalui R1 dan R2. Ketika terminal threshold (pin 6) dan trigger (pin 2) di beri tegangan, maka terjadi perubahan kondisi pada komparator 1 dan komparator 2. Komprator 1 dan 2 akan mendapatkan sinyal dan akan menyalurkan sinyal ke RS flip-flop dan menyebabkan output dari RS flip-flop berlogik 1, sehingga pin 3 IC 555 berlogik 1 juga dan menyebabkan LED hidup.

Tabel 3. Data uji coba rangkaian Astable

\begin{tabular}{|c|c|c|c|}
\hline $\mathrm{V}_{\mathrm{S}}$ & Kondisi & $\begin{array}{c}\text { Pin } \\
\text { (Terminal) }\end{array}$ & $\begin{array}{c}\text { Tegangan } \\
(\mathrm{V})\end{array}$ \\
\hline \multirow{3}{*}{$\begin{array}{c}12,17 \\
\mathrm{~V}\end{array}$} & \multirow{2}{*}{$\mathrm{SET}$} & 3(Output) & $7,44 \mathrm{~V}$ \\
\cline { 3 - 4 } & RESET & 6(Threshold) & $7,51 \mathrm{~V}$ \\
\cline { 3 - 4 } & & 7(discharger) & $14,3 \mathrm{mV}$ \\
\hline
\end{tabular}

Ketika tombol Reset di-on-kan, maka pin 4 (reset), akan terlepas dari $\mathrm{V}_{\mathrm{CC}}$, yang akan mengaktifkan transistor internal, dan transistor internal akan mereset RS flip-flop, dan output dari RS flip-flop akan berlogic 0, menyebabkan output dari IC 555 pin 3 akan OFF sehingga menyebabkan LED mati.

Dari hasil uji coba dan teori dapat dilihat pada saat Vs dihubungkan ke rangkaian, tegangan pin 6 adalah $2 / 3$ dari Vs dan pada saat reset tegangan pada pin 7 akan mulai mengosongkan muatannya.

\section{Pembuatan dan instalasi box/housing}

Pembuatan box/housing terdiri dari perancangan box, pemotongan papan maupun acrilic, digital printing rangkaian, pengeboran acrilic, instalasi gambar rangkaian ke acrilic, instalasi rangkaian PCB ke acrilic dan instalasi papan PCB beserta acrilic ke box/housing.

Dalam perancangan box disesuaikan dengan ukuran gambar rangkaian yang telah ditentukan sebelumnya. Tinggi box/housing yang akan dibuat disesuaikan dengan tinggi komponen maupun jarak papan PCB dengan acrilic yang digunakan pada media pembelajaran mini trainer IC 555. Sehingga pemotongan papan dan acrilic sesuai ukuran gambar rangkaian, dimana acrilic dipotong dengan ukuran $35 \times 23 \mathrm{~cm}$, sedangkan papan dipotong lebih besar sedikit dari acrilic.

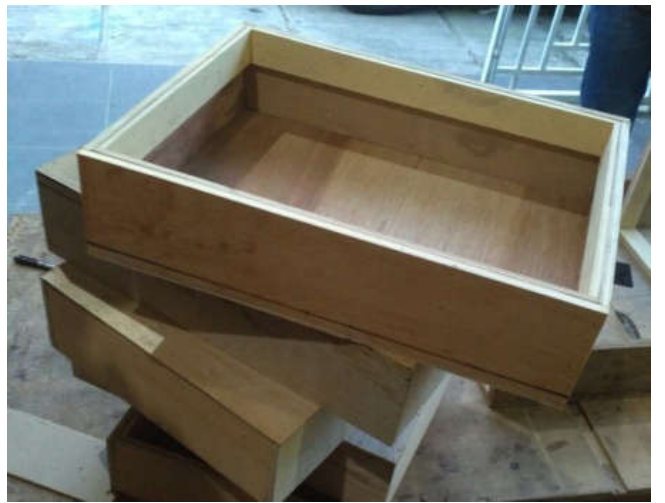

Gambar 12. Pembuatan box/housing mini trainer IC555

Gambar rangkaian yang sudah didesain sebelumnya dicetak pada kertas stiker menggunakan digital printing yang kemudian dilaminating, berikut hasilnya:

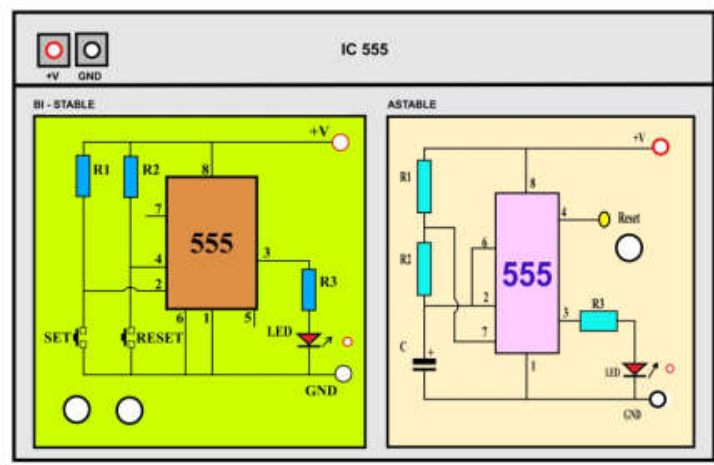

Gambar 13. Hasil print gambar mini trainer IC555

Tahap selanjutnya adalah pengeboran acrilic menggunakan mesin bor namun terlebih dahulu dengan menandai bagian acrilic yang akan dilobangkan sesuai tata letak komponen pada gambar rangkaian dengan cara menempelkan gambar rangkaian tersebut pada acrilic kemudian acrilic diberi tanda titik dengan menggunakan paku dan palu.

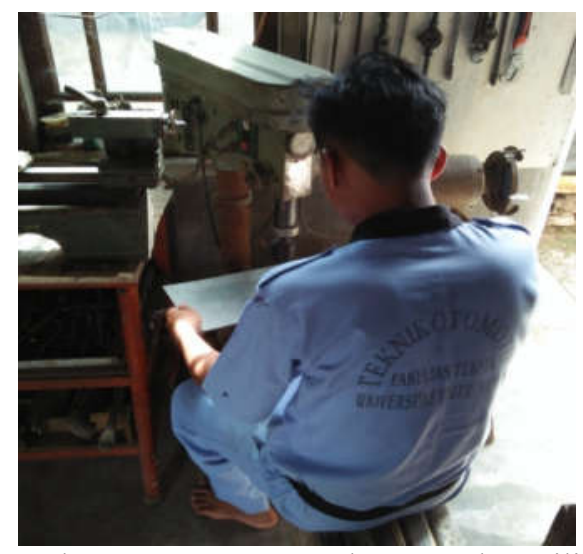

Gambar 14. Proses pengeboran pada acrilic 
Setelah acrilic dibor selanjutnya di lakukan instalasi gambar rangkaian ke acrilic.

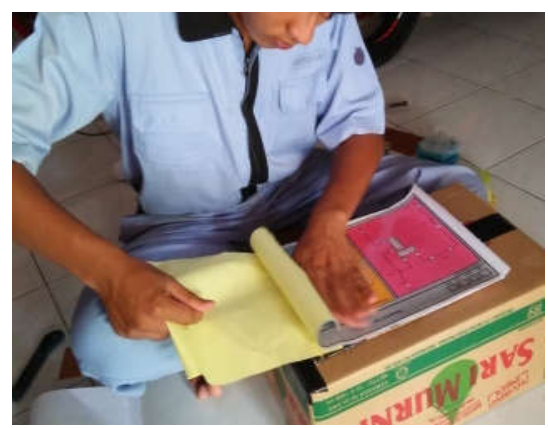

Gambar 15. Instalasi gambar rangkaian konsep dasar kelistrikan pada acrilic

Dalam melakukan instalasi rangkaian PCB ke acrilic, hal pertama yang dilakukan adalah memasang komponen ke acrilic kemudian direkatkan menggunakan lem lilin agar komponen tidak goyang, selanjutnya menghubungkan komponen dengan acrilic ke papan PCB menggunakan kabel jumper.

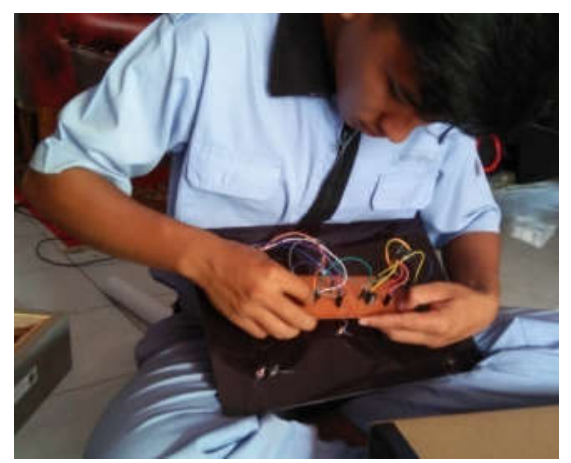

Gambar 16. Instalasi rangkaian PCB ke Acrilic IC 555

Setelah semua terpasang, kemudian dilakukan instalasi papan PCB beserta acrilic pada box/housing, berikut hasilnya:

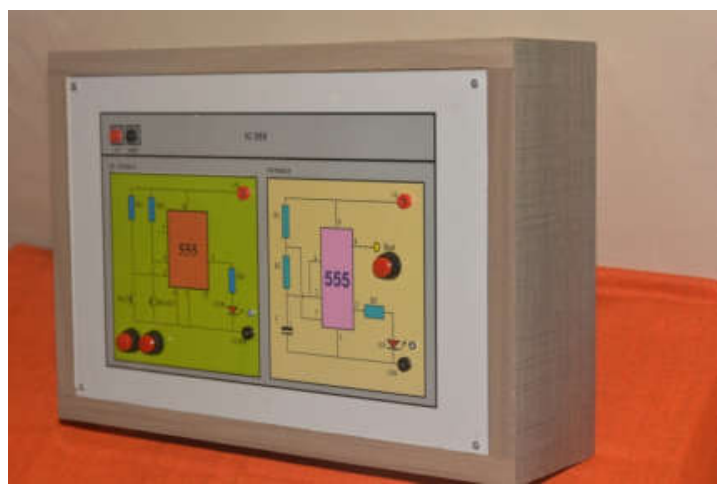

Gambar 17. Hasil instalasi rangkaian mini trainer IC 555 pada box/housing.

\section{B. Pembahasan.}

Media trainer IC 555 yang sudah selesai dinstalasi dan diberi housing seperti Gambar 17, dilakukan pengambilan data pengukuran. Hasil data pengukuran dibandingkan dengan analisa data teroritis untuk memastikan alat yang sudah jadi ini valid digunakan sebagai media pembelajaran.

1. IC 555 pada Rangkaian BI-STABIL

Tabel 4. Data hasil Pegukuran kaki-kaki IC 555 pada

\begin{tabular}{|c|c|c|c|}
\hline & Rangkaia & Bi-Stable & \\
\hline \multirow{2}{*}{ Kondisi } & \multirow{2}{*}{$\begin{array}{c}\text { Pin } \\
\text { (Terminal) }\end{array}$} & \multicolumn{2}{|c|}{ Tegangan (V) } \\
\hline & & Pengukuran & Teori \\
\hline \multirow{4}{*}{ SET } & 2 (trigger) & $3,9 \mathrm{~V}$ & $1 / 3 \mathrm{~V}_{\mathrm{S}}$ \\
\hline & 3 (output) & $10,67 \mathrm{~V}$ & $\begin{array}{c}\text { Tegangan } \\
\text { keluaran }\end{array}$ \\
\hline & $\begin{array}{c}6 \\
\text { (threshold) }\end{array}$ & $1,3 \mathrm{mV}$ & $\begin{array}{c}\text { Terhubung } \\
\text { pada masa } \\
(0 \mathrm{~V})\end{array}$ \\
\hline & $\begin{array}{c}7 \\
\text { (discharge) }\end{array}$ & $0,625 \mathrm{~V}$ & $<\mathrm{V}_{\mathrm{S}}$ \\
\hline \multirow{4}{*}{ RESET } & 2 (trigger) & $12,12 \mathrm{~V}$ & $1 / 3 \mathrm{~V}_{\mathrm{S}}$ \\
\hline & 3 (output) & $0,9 \mathrm{~V}$ & $\begin{array}{c}\text { Tegangan } \\
\text { keluaran }\end{array}$ \\
\hline & $\begin{array}{c}6 \\
\text { (threshold) }\end{array}$ & $0,9 \mathrm{mV}$ & $\begin{array}{c}\text { Terhubung } \\
\text { pada masa } \\
(0 \mathrm{~V})\end{array}$ \\
\hline & $\begin{array}{c}7 \\
\text { (discharge) }\end{array}$ & $0,406 \mathrm{~V}$ & $<\mathrm{V}_{\mathrm{S}}$ \\
\hline Vs & \multicolumn{3}{|c|}{$12,17 \mathrm{~V}$} \\
\hline
\end{tabular}

a. Tegangan pada terminal 2 (Trigger)

Tegangan pada terminal 2 dari IC haruslah 1/3 dari $\mathrm{V}_{\mathrm{S}}$, karena merupakan input negatif dari lower komparator, yang menjaga osilasi tegangan terendah kapasitor pada $1 / 3 \mathrm{~V}_{\mathrm{CC}}$ dan mengatur Rs flip-flop. Dari data yang di dapat, pada rangkaian BI-STABLE saat SET di dapat hasil 3,9 V yang sesuai dengan teori yang telah di pelajari. Dan pada saat reset didapat hasil $12,12 \mathrm{~V}$, hal ini sesuai dengan teori.

\section{b. Tegangan pada terminal 3 (Output)}

Tegangan pada terminal 3 (output) merupakan tegangan keluaran dari IC 555, jadi pada saat set keluaran dari IC 555 ada, sedangkan pada saat reset tegangan dari IC 555 hanya sedikit tersisa. 
Dari data hasil pengukuran didapat hasil pengukuran pada rangkaian $B I-S T A B L E$ pada saat $\mathrm{SET}=10,67 \mathrm{~V}$ dan pada saat RESET tegangan yang didapat adalah $0,9 \mathrm{~V}$. Dari data tersebut kita dapat hasil bahwa pada saat SET (hidup) output dari IC555 besar dan sesuai dengan teori yang ada, dan pada saat RESET (mati) output-nya pun mengecil karena tidak ada tegangan yang masuk, hanya sedikit tegangan yang tersisa.

\section{c. Tegangan pada terminal 6 (Threshold)}

Tegangan pada terminal 6 adalah tegangan dari kaki threshold yang terhubung pada massa yang me-reset RS flip-flop. Tegangan pada terminal 6 ini akan rendah karena terhubung dengan ground. Data pada rangkaian BI-STABLE pada saat set diperoleh tegangannya $1,3 \mathrm{mV}$, dan reset di dapat hasil pengukurannya $0,9 \mathrm{mV}$. Hal ini di sebabkan karena pin 6 terhubung dengan ground 0 .

\section{d. Tegangan pada terminal 7 (Dhischarge)}

Terminal 7 terhubung dengan kolektor transistor internal (Tr) dan emiter transistor terhubung dengan ground. Switching transistor ini berfungsi untuk meng-clamp node yang sesuai ke ground pada timing tertentu. Jadi dengan kata lain terminal 7 akan menghasilkan tegangan yang kecil karena terhubung langsung dengan ground. Dari data yang di dapat pada rangkain BI-STABLE pada saat SET di dapat hasil $0,625 \mathrm{~V}$, dan pada saat RESET di dapat hasil $0,406 \mathrm{~V}$ dari data ini dapat di simpulkan bahwasanya data hasil tegangan dari terminal 7 ini kecil tidak sampai $1 \mathrm{~V}$, dan tegangan pada saat set lebih besar dari pada saat reset.

\section{IC 555 pada rangkaian ASTABLE}

\section{a. Tegangan pada terminal 2(Trigger)}

Tegangan pada terminal 2 dari IC haruslah $1 / 3$ dari $V_{S}$,karena merupakan input negatif dari lower komprator yang menjaga osilasi tegangan terendah kapasitor pada $1 / 3 \quad \mathrm{~V}_{\mathrm{CC}}$ dan mengatur RS flip-flop. Pada rangkaian ASTABLE didapat hasil pengukuran pada terminal 2 saat SET adalah 7,51V dan pada saat RESET adalah 9,85V. Dari hasil pengukuran yang dilakukan di dapat kesimpulan bahwasanya tegangan pada terminal 2 (trigger) masih sesuai teori tegangan tidak boleh kurang dari 1/3 Vcc.

\section{b. Tegangan pada terminal 3 (Output)}

Tegangan pada terminal 3 ini merupakan tegangan keluaran dari IC 555, jadi pada saat set keluaran dari IC 555 ada, sedangkan pada saat reset tegangan dari IC 555 hanya sedikit tersisa dari tegangan yang tersimpan pada kapasitor. Pada Rangkaian ASTABLE data yang di dapat dari hasil pengukuran menunjukkan hasil, pada saat SET (hidup) adalah $7,44 \mathrm{~V}$,dan pada saat RESET (mati) adalah 5,4mV. Dari data pengukuran, dapat di katakan bahwa data hasil pengukuran sesuai dengan teori yang di jelaskan di atas.

Tabel 5. Data hasil pengukuran kaki-kaki IC 555 pada rangkaian $A S T A B L E$

\begin{tabular}{|c|c|c|c|}
\hline \multirow{4}{*}{ Kondisi } & \multirow{2}{*}{$\begin{array}{c}\text { Pin } \\
\text { (Terminal) }\end{array}$} & \multicolumn{2}{|c|}{ Tegangan(V) } \\
\cline { 3 - 4 } & 2 (trigger) & $7,38 \mathrm{~V}$ & $1 / 3 \mathrm{~V}_{\mathrm{S}}$ \\
\cline { 2 - 4 } SET & 3 (output) & $7,44 \mathrm{~V}$ & $\begin{array}{c}\text { Tegangan } \\
\text { keluaran }\end{array}$ \\
\cline { 2 - 4 } & 6 (threshold) & $7,51 \mathrm{~V}$ & $<2 / 3 \mathrm{~V}_{\mathrm{S}}$ \\
\cline { 2 - 4 } & 7 (discharge) & $145,5 \mathrm{mV}$ & $<\mathrm{V}_{\mathrm{S}}$ \\
\hline \multirow{5}{*}{ RESET } & 2 (trigger) & $9,85 \mathrm{~V}$ & $1 / 3 \mathrm{~V}_{\mathrm{S}}$ \\
\cline { 2 - 4 } & 3 (output) & $5,4 \mathrm{mV}$ & $\begin{array}{c}\text { Tegangan } \\
\text { keluaran }\end{array}$ \\
\cline { 2 - 4 } & 6 (threshold) & $9,89 \mathrm{~V}$ & $<2 / 3 \mathrm{~V}_{\mathrm{S}}$ \\
\cline { 2 - 4 } & 7 (discharge) & $14,3 \mathrm{mV}$ & $<\mathrm{V}_{\mathrm{S}}$ \\
\hline Vs & & $12,11 \mathrm{~V}$ & \\
\hline
\end{tabular}

\section{c. Tegangan pada terminal 6 (Threshold)}

Tegangan pada terminal 6 adalah tegangan dari terminal threshold yang terhubung pada input positif yang me-reset RS flip-flop ketika tegangan ini mulai melebihi $2 / 3 \mathrm{Vcc}$, jadi dapat dikatakan tegangan pada terminal 6 ini tidak melebihi 2/3 dari Vcc. Pada Rangkaian ASTABLE di dapat hasil pengukuran pada saat SET adalah $7,51 \mathrm{~V}$ dan pada saat RESET di dapat hasil $9,8 \mathrm{mV}$, data ini juga sesuai dengan kajian teoritis.

\section{d. Tegangan pada terminal 7 (Dhischarge)}

Terminal 7 ini terhubung pada kolektor transistor internal (Tr) yang emiternya terhubung dengan ground. Switching transistor ini berfungsi untuk meng-clamp node yang sesuai ke ground pada timing tertentu. Jadi dengan kata lain terminal 7 akan menghasilkan tegangan yang kecil karena dia berhubungan langsung dengan ground. Pada rangkaian ASTABLE, di dapat hasil 
pengukuran, pada saat SET $145,5 \mathrm{mV}$ dan pada saat RESET $14,3 \mathrm{mV}$.

\section{KESIMPULAN}

Proses perakitan mini trainer IC 555 terdiri dari perancangan gambar, perakitan komponen, uji coba rangkaian, instalasi housing, serta pengambilan data data dan analisa data. Mini trainer yang dirancang, sudah divalidasi dengan cara mensinkronkan data pengukuran dengan kajian teoritis. Berdasarkan analisa data di pembahasan dapat disimpulkan mini trainer IC 555 sudah sesuai dengan kajian teoritis, sehingga dapat digunakan sebagai media pembelajaran

\section{DAfTAR PUSTAKa}

[1] Basri, IY,. \& Adri, M. (2011). Pemanfaatan Animasi Multimedia pada Mata Kuliah Kimia Teknik untuk Peingkatan Pemahaman Mahasiswa terhadap Konsep Kimia. Jurnal teknologi Informasi dan Pendidikan. Volume 4, No 1 Edisi September 2011.

[2] Sukmawardana, Y., dkk. (2016). Pembuatan Media Pembelajaran Trainer Instalasi Listrik Penerangan pada Mata Pembelajaran Instalasi Listrik Untuk Meningkatkan hasil belajar Siswa Kelas XI SMK PGRI 1 Mijayan tahun Pelajaran 2015/2016. Jurnal Pendidikan Teknik Elektro. Volume 1, Nomor 2 Edisi Oktober 2016, 70-76.

[3] Hastuti,. dkk. (2017). Penerapan Trainer Omron sebagai Media Pembelajaran Mata Diklat Instalasi Motor Listrik. Jurnal Invotek. Volume 17, No 1 Edisi April 2017.

[4] Haryawan, A. Salechan. 2017. Pengembangan Bahan Ajar Mikrokontroler Berbasis Arduino Sebagai Media Pembelajaran Mata Kuliah Mikrokontroler di Politeknik Pratama Mulia Surakarta. POLITEKNOSAINS, Vol. XVI, No 2, September 2017

[5] Susilo \& Suyitno. (2017). Pengembangan Media Pembelajaran Trainer Kelistrikan untuk meningkatkan Hasil belajar Siswa SMK Muhammadiyah Kutowinangun. Jurnal Pendidikan Teknik Otomotif Universitas Muhammadiyah Purwokerto. Volume 10, No 10 Edisi Juli 2017.

[6] Bishop, Owen. 2002. Dasar-Dasar Elektronika. Jakarta: Erlangga.

[7] Blocher, Richard. 2004. Dasar Elektronika. Yokyakarta: Andi.
[8] Daryanto. 2011. Pengetahuan Teknik Eloktronika. Malang: Bumi Aksara.

[9] Malvino, Albert Paul. 1996. Prinsip-Prinsip Elektronika(jilid 2). Jakarta: Erlangga.

[10] Sugiyono. (2013). Metode Penelitian Pendidikn Pendekaran Kuantitatif, Kualitatif dan $R \& D$. Bandung: Alfabeta

\section{BiodataPenulis}

Irma Yulia Basri, merupakan dosen Jurusan Teknik Otomotif FT UNP, dengan latar Pendidikan S1 Pendidikan Teknik Elektronika FT UNP, S2 Teknik Elektro UGM.

Arsyfadhillah, merupakan Mahasiswa Teknik Otomotif yang tugas akhirnya tergabung dalam tim penelitian penulis pertama.

Dedy Irfan, merupakan dosen Jurusan Teknik Elektronika FT UNP, dengan latar Pendidikan S1 Pendidikan Teknik Elektronika FT UNP, S2 Teknik Komputer UPI dan S3 Pendidikan Pasca Sarjana UNP.

Thamrin, merupakan dosen Jurusan Teknik Elektronika FT UNP, dengan latar Pendidikan S1 Pendidikan Teknik Elektronika FT UNP, S2 Teknik Elektro UNAND. 